\title{
Article \\ A Robust Method for Detecting Wind-Fallen Stems from Aerial RGB Images Using a Line Segment Detection Algorithm
}

\author{
Tim Ritter ${ }^{1, *}{ }^{\mathbb{C}}$, Christoph Gollob $^{1}{ }^{1}$, Ralf Kraßnitzer ${ }^{1}$, Karl Stampfer $^{2}$ and Arne Nothdurft ${ }^{1}$ (D) \\ 1 Department of Forest and Soil Sciences, Institute of Forest Growth, University of Natural Resources and Life \\ Sciences, 1190 Vienna, Austria; christoph.gollob@boku.ac.at (C.G.); ralf.krassnitzer@boku.ac.at (R.K.); \\ arne.nothdurft@boku.ac.at (A.N.) \\ 2 Department of Forest and Soil Sciences, Institute of Forest Engineering, University of Natural Resources and \\ Life Sciences, 1190 Vienna, Austria; karl.stampfer@boku.ac.at \\ * Correspondence: tim.ritter@boku.ac.at
}

Citation: Ritter, T.; Gollob, C.; Kraßnitzer, R.; Stampfer, K.; Nothdurft, A. A Robust Method for Detecting Wind-Fallen Stems from Aerial RGB Images Using a Line Segment Detection Algorithm. Forests 2022, 13, 90. https://doi.org/ $10.3390 /$ f13010090

Academic Editor: Svein Solberg

Received: 2 December 2021

Accepted: 5 January 2022

Published: 8 January 2022

Publisher's Note: MDPI stays neutral with regard to jurisdictional claims in published maps and institutional affiliations.

Copyright: (C) 2022 by the authors. Licensee MDPI, Basel, Switzerland. This article is an open access article distributed under the terms and conditions of the Creative Commons Attribution (CC BY) license (https:// creativecommons.org/licenses/by/ $4.0 /)$.

\begin{abstract}
Increased frequencies and windspeeds of storms may cause disproportionately high increases in windthrow damage. Storm-felled trees provide a surplus of breeding material for bark beetles, often resulting in calamities in the subsequent years. Thus, the timely removal of fallen trees is regarded as a good management practice that requires strategic planning of salvage harvesting. Precise information on the number of stems and their location and orientation are needed for the efficient planning of strip roads and/or cable yarding lines. An accurate assessment of these data using conventional field-based methods is very difficult and time-consuming; remote sensing techniques may be a cost-efficient alternative. In this research, a methodology for the automatic detection of fallen stems from aerial RGB images is presented. The presented methodology was based on a line segment detection algorithm and proved to be robust regarding image quality. It was shown that the method can detect frequency, position, spatial distribution and orientation of fallen stems with high accuracy, while stem lengths were systematically underestimated. The methodology can be used for the optimized planning of salvage harvesting in the future and may thus help to reduce consequential bark beetle calamities after storm events.
\end{abstract}

Keywords: windthrow; storm damage; salvage logging planning; remote sensing; image interpretation

\section{Introduction}

For the period 1950-2000, 53\% of timber loss in European forests was due to storm damage, in particular, the alpine zone of mountainous regions was heavily affected by storms [1].

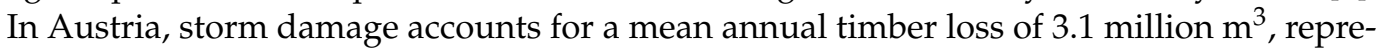
senting $12 \%$ of the total annual fellings [2].

Increased frequencies and windspeeds of storms may cause disproportionately high increases in windthrow damage [3]. In Switzerland, during the period 1958-2007, storm damage was 17 times greater than during the period 1908-1957 and 22 times greater than in the period 1858-1907, this steep increase can only partially be explained by increased growing stock volume [4]. In $96 \%$ of all cases, severe storm damage occurred when soils were unfrozen and wet; during the observation period, the mean winter temperature in Switzerland increased by nearly $2 \mathrm{~K}$, winter precipitation increased by nearly $50 \%$, the maximum measured gust wind speed increased by $37 \%$ and the average number of strong gust wind speed events per winter half-year increased by a factor of 11.9 [4]. Presumably, the future amount of storm damage in Europe will further increase due to a higher frequency of storm events and higher maximum wind speeds [5-7].

In particular, Norway spruce (Picea abies (L.) H. Karst.) forests are heavily affected by storm damage [8]. Storm-felled spruce trees provide a surplus of breeding material for bark beetles, often resulting in calamities in the subsequent years [9]. Thus, the timely removal of fallen trees is regarded as a good forest management practice [10] that requires 
strategic planning of salvage harvesting [11]. Clearing windthrown wood is one of the most dangerous tasks in forest operations and requires detailed operation planning to minimize occupational risks $[12,13]$. Chaotic windthrow patterns (i.e., stems oriented in different directions), caused by whirlwinds, make harvest operations even more complicated and expensive than uniform patterns of windthrow (i.e., stems orientated approx. parallel), caused by straight-line winds $[14,15]$. The decision for a specific salvage harvesting and extraction system [16] should depend on the type and severity of the damage, the windthrow pattern and the spatial distribution of the felled trees [15]. Typically, fallen stems are assessed using field surveys [17]; however, these are usually time consuming and labor intensive [18], especially in cases where the spatial distribution of fallen stems over a wide area has to be assessed. Remote sensing techniques may be a cost-efficient alternative [18-20]. Several studies [21-26] successfully demonstrated the detection of blowdown areas from satellite data. However, for the planning of strip roads and/or cable yarding lines, it is mandatory to detect individual stems. Thus, a resolution at the level of one or two decimeters or better is crucial to the detection success because the width of the stem is on that scale. Available satellite data (still) do not offer such a high resolution. A number of recent contributions focused on the detection of fallen stems from airborne and terrestrial laser scanning data [27-29], and while the laser scanning point clouds proved to be a solid data basis for fallen tree detection, data availability may be limited and are associated with high acquisitions costs.

Aerial images obtained using manned or unmanned aerial vehicles are more accessible than laser scanning data. Multi-spectral aerial images are particularly useful, since dead and diseased vegetation produces a distinct reflectance signature in the near-infrared band [30]; however, many sensor systems are limited to RGB imagery. Approaches to the detection of individual fallen trees from aerial RGB images [31-33] or multi-color infrared images [19] are still very rare. Existing approaches can be grouped into two categories: (i) determining lines that represent the positions and lengths of individual stems, disregarding stem diameters [31,32]; and (ii) extracting 2D polygons representing individual stems $[19,33]$ so that the widths of the polygons resemble stem diameters. Obviously, the latter approach has the principal advantage that stem diameters can also be assessed. However, this requires a higher spatial resolution of the image data; only in cases where the pixel size is substantially smaller than the stem diameter can the polygon fitting be accurate enough to obtain meaningful stem diameter estimates.

Given the necessity of the timely removal of fallen trees, information is urgently needed in a close temporal context to the storm event. Therefore, it is often impossible to obtain aerial images of the highest quality due to the constraints of available sensors and sensor platforms and non-optimal weather conditions during image acquisition. Furthermore, in larger areas, data quality is often heterogeneous, as data acquisition takes a substantial amount of time such that weather conditions differ during the sampling campaign. In cases where data acquisition is done by different commercial operators, different sensor systems might also contribute to data heterogeneity.

The area under investigation is located in the Gailtal Valley, in the Austrian federal state Carinthia. The area was hit by storm Adrian/Vaia in October 2018, resulting in a growing stock volume loss of 133,775 $\mathrm{m}^{3}$ [34]. A total of 564 blowdown areas (212.3 ha in total) were manually identified by the Carinthian forest service. In 36 randomly selected sample blowdown areas, all stems (6794 in total) were manually digitized as reference. The available aerial images for the sample areas differed with respect to the sensor, spatial resolution, exposure, contrast, cloud coverage and shadows.

We hypothesized that it is possible to automatically detect individual wind-fallen stems and to automatically extract the necessary information for salvage harvesting planning from existing aerial images of heterogeneous quality.

Thus, the goal of this research was to develop an approach for the automatic assessment of individual downed stems from RGB aerial images that is robust with respect to spatial resolution and image quality. We present an approach that is based on the 
line segment detection (LSD) algorithm by Grompone von Gioi et al. [35], where the presented approach showed reasonably high consistency with the reference data with respect to the stem number, the distribution of azimuth angles and the spatial distribution of stems on the plots. Only the lengths of the individual stems were poorly estimated, i.e., systematically underestimated.

The novel approach aimed toward the detection of single fallen stems in blowdown areas that were already identified. It is not intended to replace proven algorithms for blowdown area detection [21-26].

\section{Materials and Methods}

\subsection{Area under Investigation}

The area under investigation (Figure 1) was located near the border between Austria and Italy and covered five forest districts (Frohn, Liesing, Mauthen, Laas and Ploecken) of the Gailtal area in the political district Hermagor of the Austrian federal state Carinthia. The area was hit by storm Adrian/Vaia on 28-30 October 2018, inflicting heavy damage on the region's forest and infrastructure [36]. Gust wind speeds exceeded $130 \mathrm{~km} / \mathrm{h}$, and within $72 \mathrm{~h}, 627 \mathrm{~L} / \mathrm{m}^{2}$ of precipitation were measured at the meteorological station Ploeckenpass, which is in proximity to the area under investigation. The total loss of growing stock volume was estimated at $1,500,000 \mathrm{~m}^{3}$ in the federal state of Carinthia [37]. In the area under investigation, 564 blowdown areas (212.3 ha in total) were manually identified by the Carinthian forest service and the total loss of growing stock volume was estimated at $133,775 \mathrm{~m}^{3}$ [34].
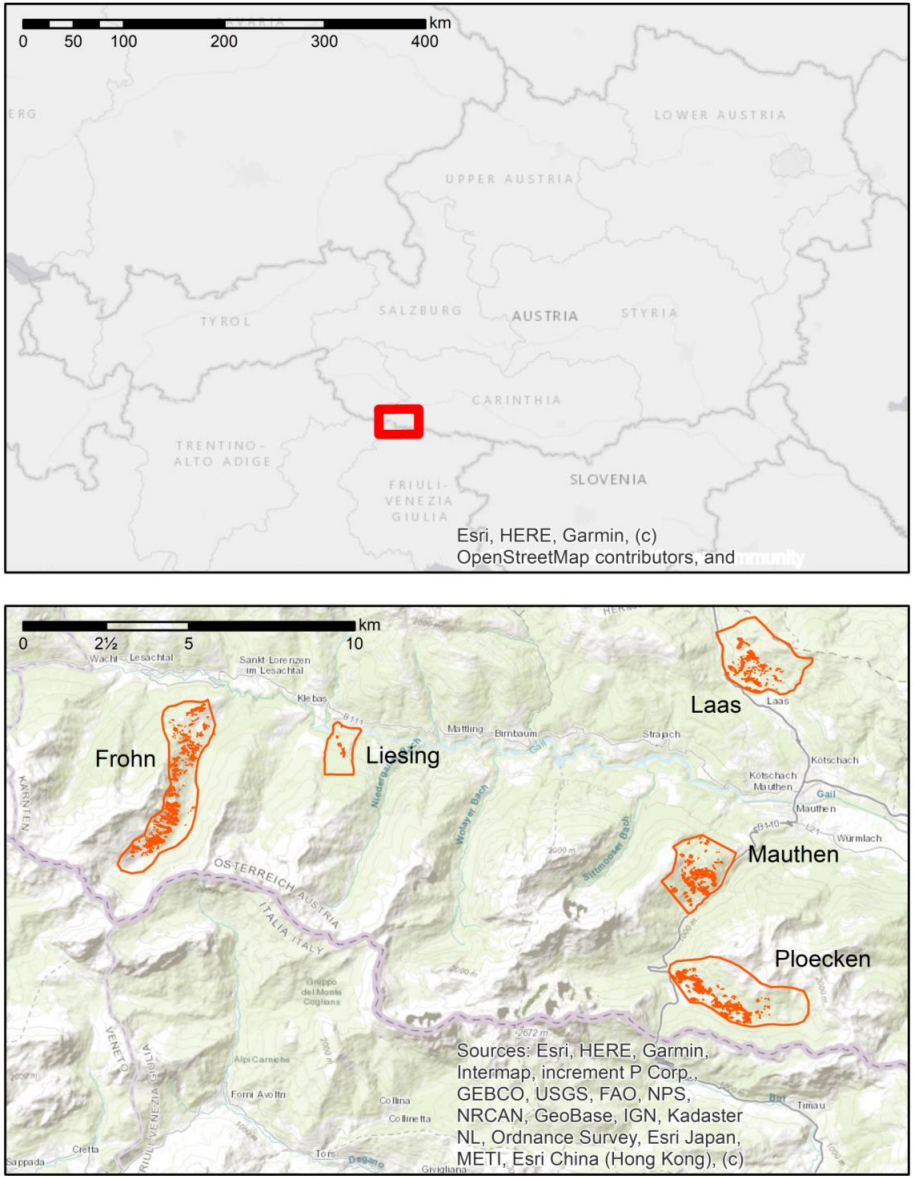

Figure 1. Location of the area under investigation in Austria, and locations of the blowdown areas in the five forest districts (Frohn, Liesing, Laas, Mauthen and Ploecken). Forest district borders are represented by the orange polygon lines, windthrow areas within the forest subdistricts are represented by orange-filled polygons. 


\subsection{Aerial Images}

Aerial RGB images (orthomosaics in GeoTiff format) were obtained on behalf of the Carinthian forest service by several commercial operators. Therefore, images were obtained using different sensors, on different platforms (UAV and airplane) and under different lighting and weather conditions. Thus, the images showed remarkable differences in white balance, exposure, contrast, shadows and cloud coverage (Figure 2).
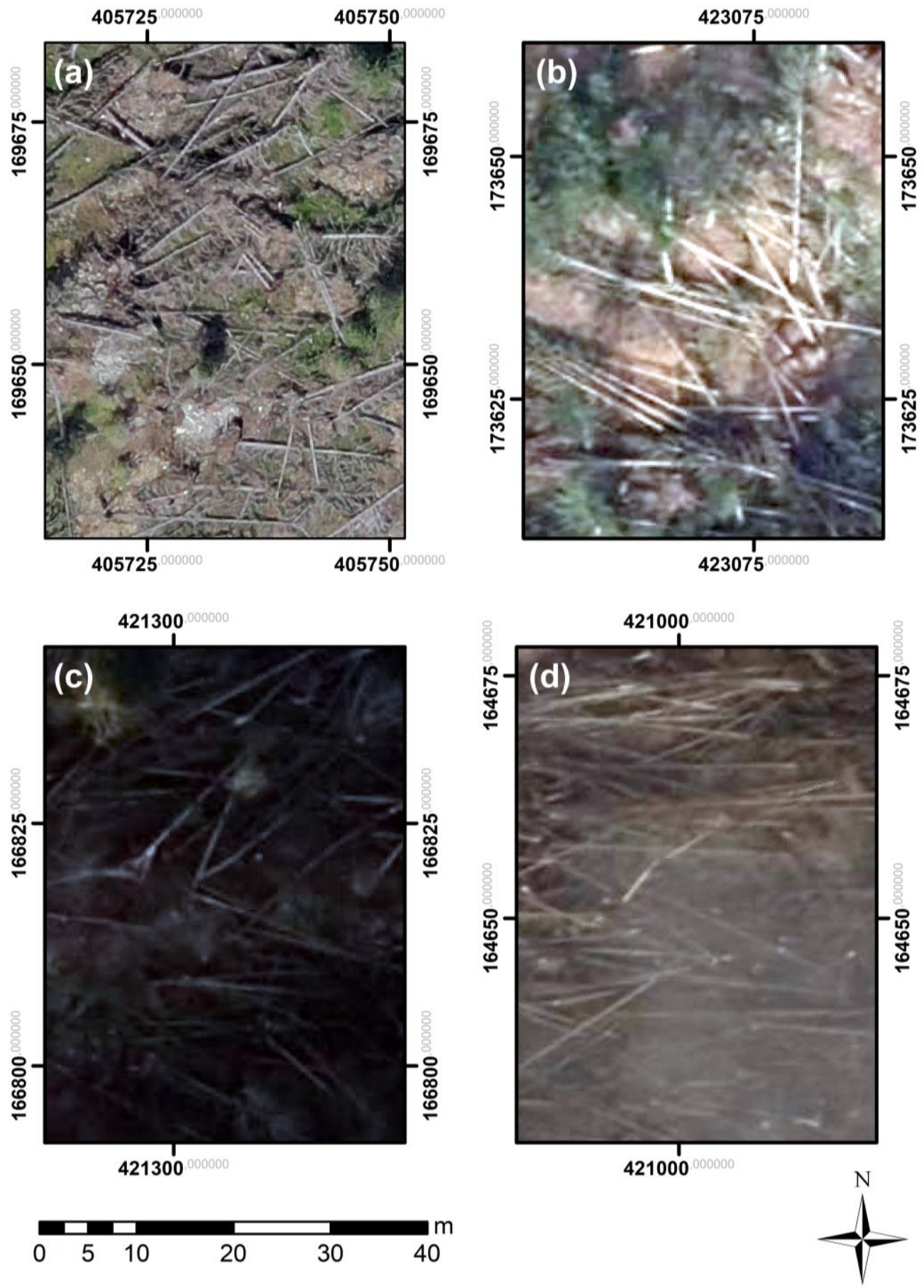

Figure 2. Exemplary aerial images with different ground sampling distance (GSD) and different quality; coordinates are in the "MGI/Austria GK M31" coordinate reference system (EPSG-code: 31258): (a) an optimal image, GSD = $11.84 \mathrm{~cm}$; (b) an image with harsh shadows, GSD = $20.02 \mathrm{~cm}$; (c) an underexposed image, GSD $=19.99 \mathrm{~cm}$; and $(\mathbf{d})$ an image with clouds and low contrast, $\mathrm{GSD}=20.02 \mathrm{~cm}$. 
Due to different sensor resolutions and flight heights, the ground sample distance (GSD) of the different images ranged between $11.84 \mathrm{~cm}$ and $20.02 \mathrm{~cm}$, with a mean value of $18.16 \mathrm{~cm}$ (Figure 3).

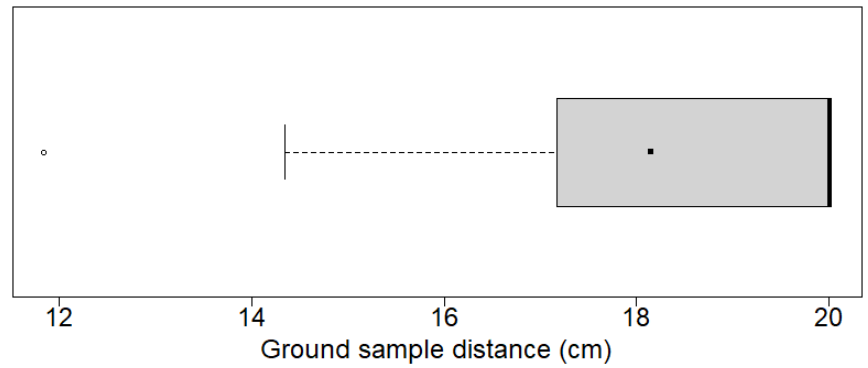

Figure 3. Ground sample distance of the aerial images of the 36 sample blowdown areas.

\subsection{Reference Data}

A sample of 36 blowdown areas was randomly selected from the 564 blowdown areas. Sample sites were negatively buffered by $20 \mathrm{~m}$ to exclude edge effects on the stand borders, then all stems visible in the aerial images (6794 in total) were manually digitized as references using ESRI ArcGIS Desktop 10.7 [38]. The mean size of the sample blowdown areas (after negative buffering) was $1.11 \mathrm{ha}$, and the corresponding range was $0.42 \mathrm{ha}$ to 2.45 ha. In the individual sample blowdown areas, between 41 and 451 (mean = 189) downed trees were observed. The corresponding range of downed trees per hectare was 65.3 to 416.1 (mean $=182.0)$.

The sample site Frohn_02 (Figure 4) was selected as an exemplary presentation of detailed results because it was a relatively small site $(0.45$ ha) with only a relatively low number of stems (115) such that the perceptibility of the figures was enhanced. Yet, all the main findings can be demonstrated with this site. Summarized results are presented for all sample sites.

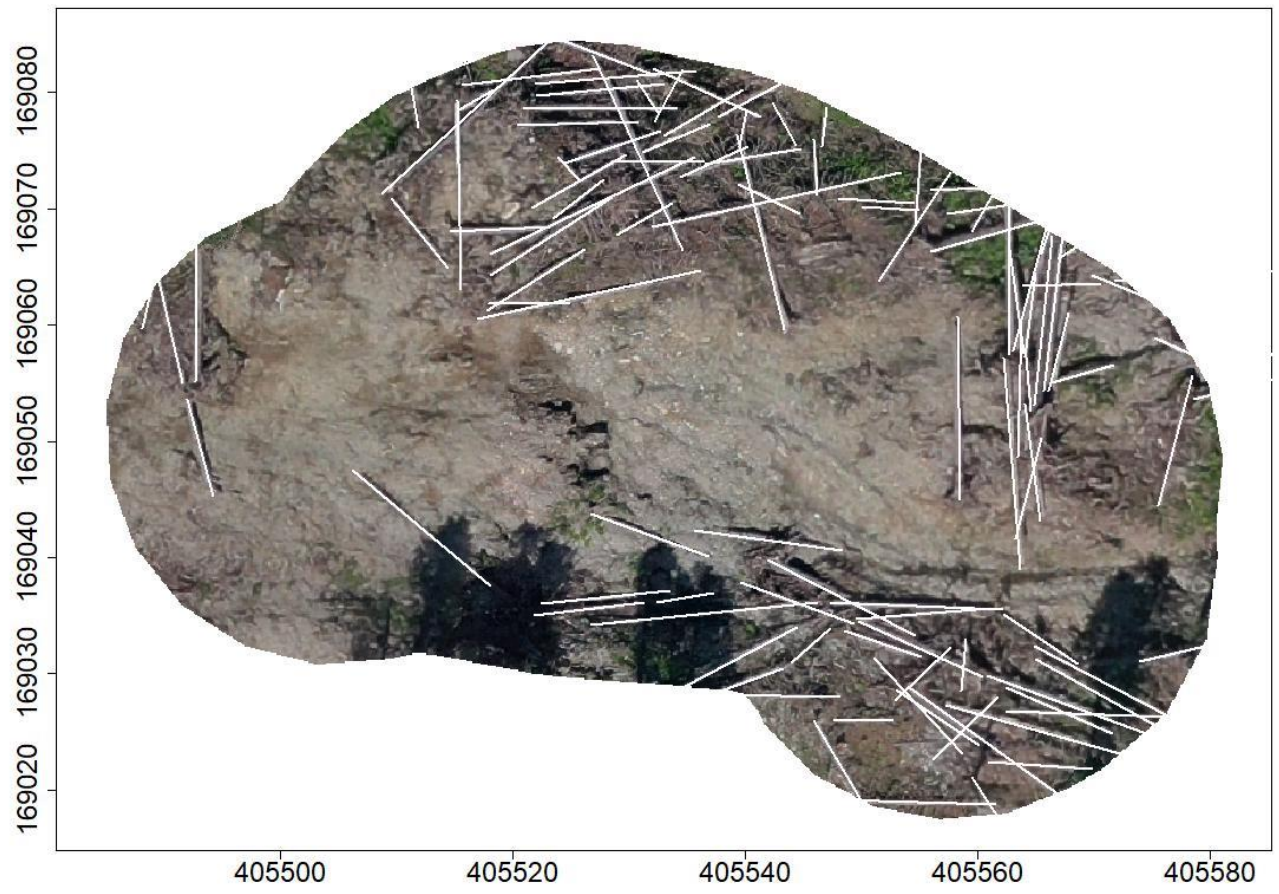

Figure 4. Manually digitized stems (white lines) on the exemplary sample site Frohn_02. Coordinates are in meters and in the "MGI/Austria GK M31" coordinate reference system (EPSG-code: 31258). 


\subsection{Stem Detection}

The workflow of the automatic stem detection (Figure 5) was completely implemented in the R statistical language and environment [39].

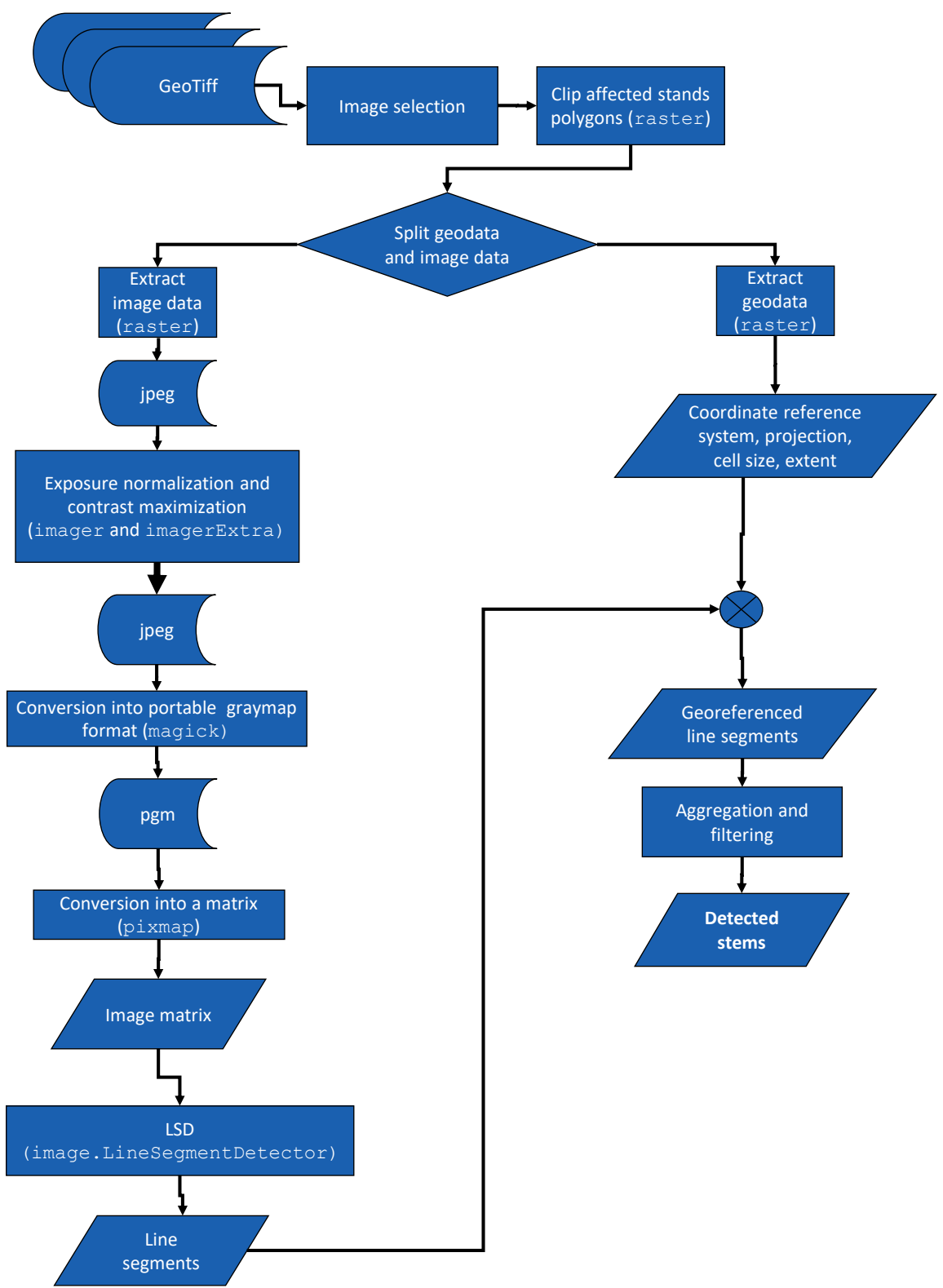

Figure 5. Workflow of the automatic stem detection.

\subsubsection{Image Selection and Preparation}

The GeoTiff files (RGB orthomosaics) provided by the Carinthian Forest Service were filtered by the date of image acquisition (after the storm event but prior to any forest operations for clearing the windthrow). In the rare cases where more than one image covered a sample area, the image with the lowest percentage of cloud cover was manually selected. The selected image was then clipped to the sample area using the polygons provided by the Carinthian Forest Service and the R package "raster" [40].

As not all image analysis tools in the workflow were able to handle the GeoTiff file format, the geodata and image data were split using the R package "raster". Geodata (i.e., the coordinate reference system, projection, cell size and extent) were extracted from the GeoTiff world files and saved as an R object of the class data frame, while the image data were converted to the jpeg format. 
The different aerial RGB images were obtained under very different lighting conditions, and therefore, showed remarkable differences in white balance, exposure and contrast (Figure 2). Thus, the RGB images were converted to a greyscale image (Figure 6) via a linear approximation to the luminance (LUMA) using the function "grayscale" from the R package "imager" [41]. Then, the contrast of the greyscale images was optimized via piecewise affine histogram equalization using the function "EqualizePiecewise" from the $R$ package "imagerExtra" [42]. Afterward, the exposure of the image was normalized to the 0-255 range (Figure 6), and the jpeg image was converted into the pgm (portable graymap) format using the R package "magick" [43]. The pgm file was then re-imported to $\mathrm{R}$ as an object of the class image matrix using the package "pixmap" [44].
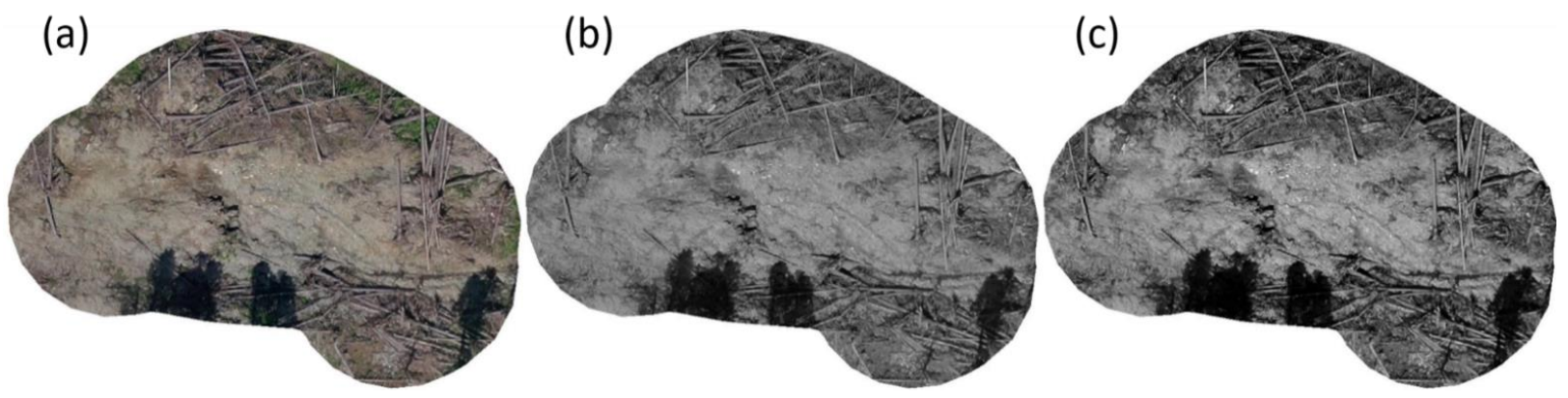

Figure 6. Automated image preparation of exemplary sample site Frohn_02: (a) RGB image; (b) greyscale image obtained via linear approximation to the luminance; and (c) optimized greyscale image after piecewise affine histogram equalization and exposure normalization.

\subsubsection{Line Segment Detection}

The image matrix $i$ was used for the line segment detection with the LSD algorithm [35] implemented in the R package "image.LineSegmentDetector" [45]. LSD is a linear-time line segment detector that is designed to work on any digital image without parameter tuning and is capable of providing results with subpixel accuracy [35]. LSD controls its own number of false detections [46]. In the following, we only provide a short description of the algorithm; for further details were refer to Grompone von Gioi et al. [35].

The algorithm starts by computing the level-line angle at every pixel, i.e., the direction of the lowest contrast between the actual pixel and the neighboring pixels, to produce a unit vector field such that all vectors are tangent to the level line going through their base point. Then, this vector field is segmented into so-called line support regions, i.e., connected regions of pixels that share the same level-line angle and that are used as candidates for line segments. For every line support region, a rectangle $r$ with the same main direction as the level-line angle of the line support region is chosen to cover the full line support region [35].

After the selection of line segment candidates, a validation procedure based on the a contrario approach and the Helmholtz principle $[47,48]$ is carried out. Within $r$, the total number of pixels and its number of aligned points are counted and tested against the expected values under the a contrario model $\mathrm{H}_{0}$, i.e., a noise model for the image gradient orientation. For this, it is necessary to compute all possible rectangles that have the same size and orientation as $r$ that can be placed in an image having the same dimensions as $i$. The expected number of false alarms (NFA), i.e., the expected number of rectangles with a sufficient number of aligned points to be as rare as $r$ under $\mathrm{H}_{0}$, is then computed. Finally, a threshold $\varepsilon$ is selected, and in the case where $\operatorname{NFA}(r, i) \leq \varepsilon$, the rectangle $r$ is considered an $\varepsilon$-meaningful rectangle and accepted as a line segment [35]. In this research, the default value $\log (\varepsilon)=0$ of the R package "image.LineSegmentDetector" [45] was used. This corresponds to the recommendation by Desolneux, Moisan and Morel $[47,48]$ to set $\varepsilon=1$, i.e., to accept an average of one false detection per image under $\mathrm{H}_{0}$. 
The coordinates of the detected line segments were then transformed back into the original coordinate reference system that was extracted from the GeoTiff images at the start of the analysis, yielding a layer of georeferenced line segments.

At this point, it must be emphasized that the line segments did not necessarily represent stems. The LSD found all kinds of different linear structures on the images, e.g., skidding tracks, rock edges and shadows, and the actual number of falsely detected stems may thus be much higher than $\varepsilon=1$ per image. Moreover, several line segments may belong to the same stem. Therefore, we used the following heuristic procedure to select the stems from the line segments.

\subsubsection{Aggregation and Filtering of Line Segments for Stem Detection}

In the first step, a negative buffer of $0.5 \mathrm{~m}$ was applied to the image, and all line segments having their centroid within the buffer area were removed. This was done to remove line segments that resulted from the border between data and no-data cells. Afterward, the region around the extension $\left( \pm 5^{\circ}\right)$ of every line segment was searched for other line segments within an $8 \mathrm{~m}$ distance from the initial line. In cases where a line segment was found that was approximately parallel to the initial line segment $\left( \pm 5^{\circ}\right)$, these two line segments were merged. The reason for this was that many stems were only partially visible due to other stems lying crosswise over them so that several distinct line segments belonged to one stem.

In the final, step, Jenks' natural breaks classification [49] implemented in the R package BAMMtools [50] was used to differentiate between two classes of line segments (short and long) by minimizing the sum of squared deviations from the class means. Line segments classified as short were removed, as these mostly represented objects different than stems, mainly rock edges.

\subsection{Evaluation of Accuracy}

Especially for piles of stems (e.g., Figure 2d), it was not possible to unambiguously assign automatically detected stems to reference stems. Thus, calculations of commission and omission errors were not possible. Instead, the number, spatial distribution and orientations of the automatically detected stems with the reference were compared.

The spatial distribution of stems was assessed using an axis-aligned bivariate Gaussian kernel density estimation (KDE) of the stem centroids using the "kde2d" function from the R package "MASS" [51]. The spatial distribution of stems was then compared to the reference using a Fasano-Franceschini test, i.e., an extension of the Kolmogorov-Smirnov test for twodimensional distributions implemented in the R package "fasano.franceschini.test" [52].

Orientation of the stems was measured in degrees as a deviation from the north-south orientation (azimuth). As the methodology outlined above did not allow for differentiation between the top and base of the stems, only the $0^{\circ}$ to $180^{\circ}$ range was regarded. Angles larger than $180^{\circ}$ were transformed to the $0^{\circ}$ to $180^{\circ}$ range by inverting the direction of measurement, i.e., simply by subtracting $180^{\circ}$ from the initial measurement. The distribution of azimuths was then compared with the reference data using a Kolmogorov-Smirnov test.

Image-wise tests of the spatial distributions of the stems and their orientation for all 36 sample blowdown areas raised the problem of alpha inflation associated with multiple testing [53]. Therefore, we used Holm's sequential Bonferroni procedure [54] to correct the $p$-values resulting from the multiple testing.

\section{Results}

\subsection{Results for Exemplary Sample Site Frohn_02}

The initial line segment detection (Figure 7a) produced many artifacts at the border between the data and no-data cells; these were completely removed by the negative buffering (Figure $7 \mathrm{~b}$ ). The union of line segments (Figure 7c) became effective, especially in cases where stems were piled on top of each other. At this stage, there were still many false detections, mainly due to rock edges that could mostly be removed by Jenks' natural break 
classification (Figure 7d). Finally, 114 stems were automatically detected, corresponding well with the manual reference of 113 stems.
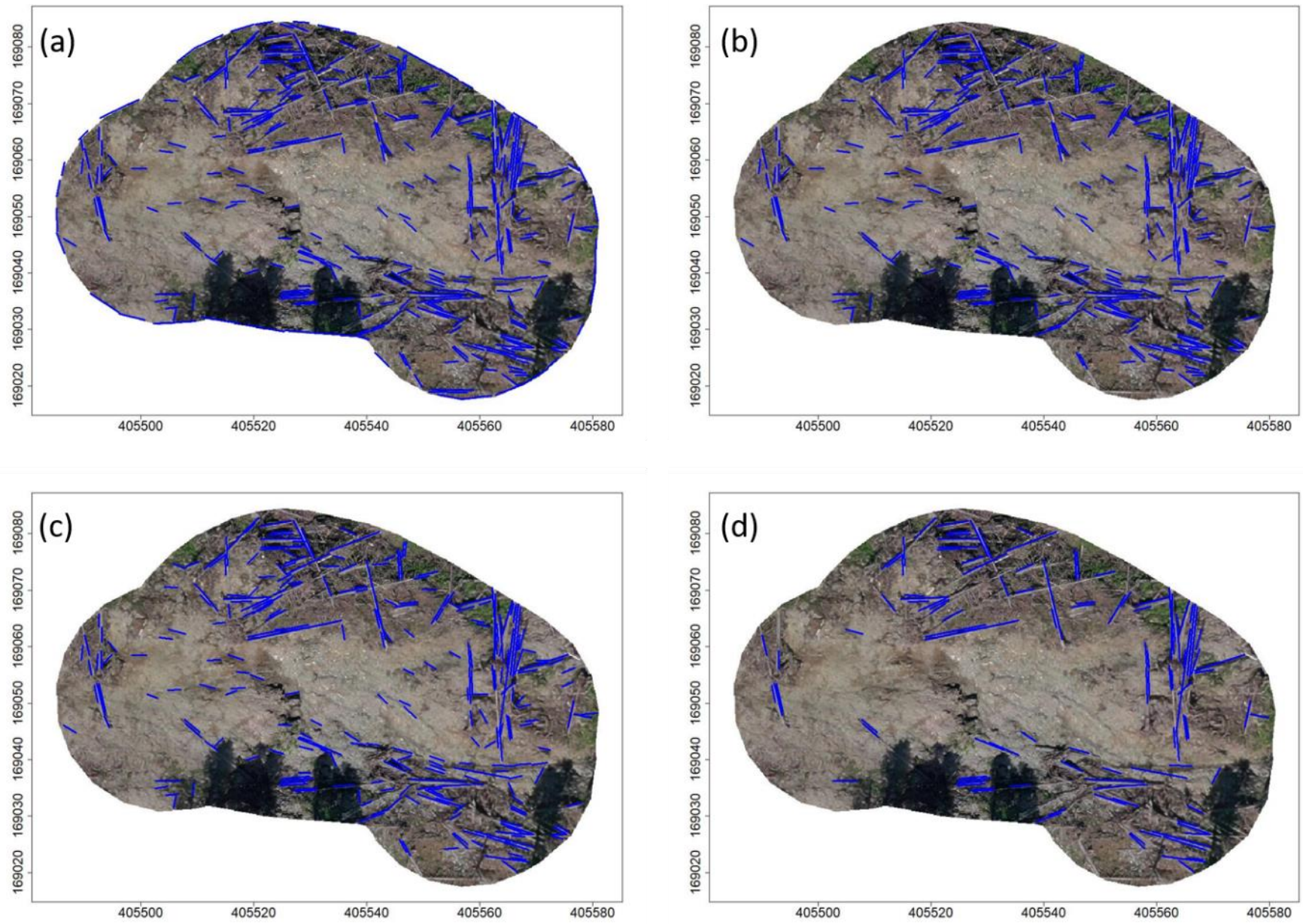

Figure 7. Results of the automated stem detection (blue lines) on sample site Frohn_02. Coordinates are in meters and in the "MGI/Austria GK M31" coordinate reference system (EPSG-code: 31258): (a) all detected line segments; (b) remaining line segments after negative buffering of $0.5 \mathrm{~m}$; (c) union of line segments that may belong to one stem; and (d) removal of short line segments using Jenks natural breaks classification.

The KDE of the spatial distribution of stem centroids obtained using automatic detection and the reference was very similar (Figure 8). According to a Fasano-Franceschini test, there was no statistically significant difference $(p=0.70)$ between the spatial distribution of stem centroids obtained using automatic detection and the reference data.

There was no statistically significant difference $(p=0.28)$ between the distribution of stem orientation (azimuth) obtained using automatic detection and reference data (Figure 9) according to a Kolmogorov-Smirnov test. The distribution of azimuths was bimodal, showing peaks at around $90^{\circ}$ (west-east oriented) and at around $0^{\circ} / 180^{\circ}$ (north-south oriented).

The distribution of the stem lengths obtained with the automatic procedure showed a statistically significant difference from the reference data (Kolmogorov-Smirnov test: $p<0.001$ ), and a clear underestimation of the stem lengths became obvious (Figure 10). 

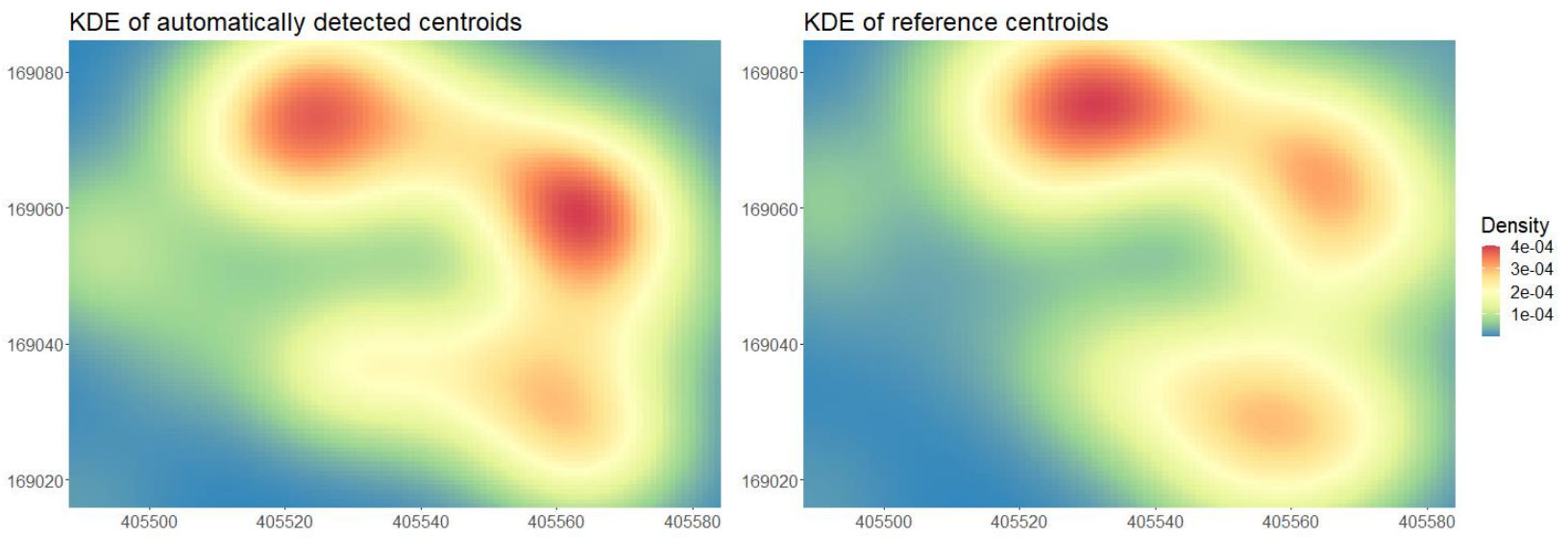

Figure 8. Kernel density estimation (KDE) of the stem centroid positions obtained via automatic detection and reference data on the exemplary sample site Frohn_02. Coordinates are in meters and in the "MGI/ Austria GK M31" coordinate reference system (EPSG-code: 31258).
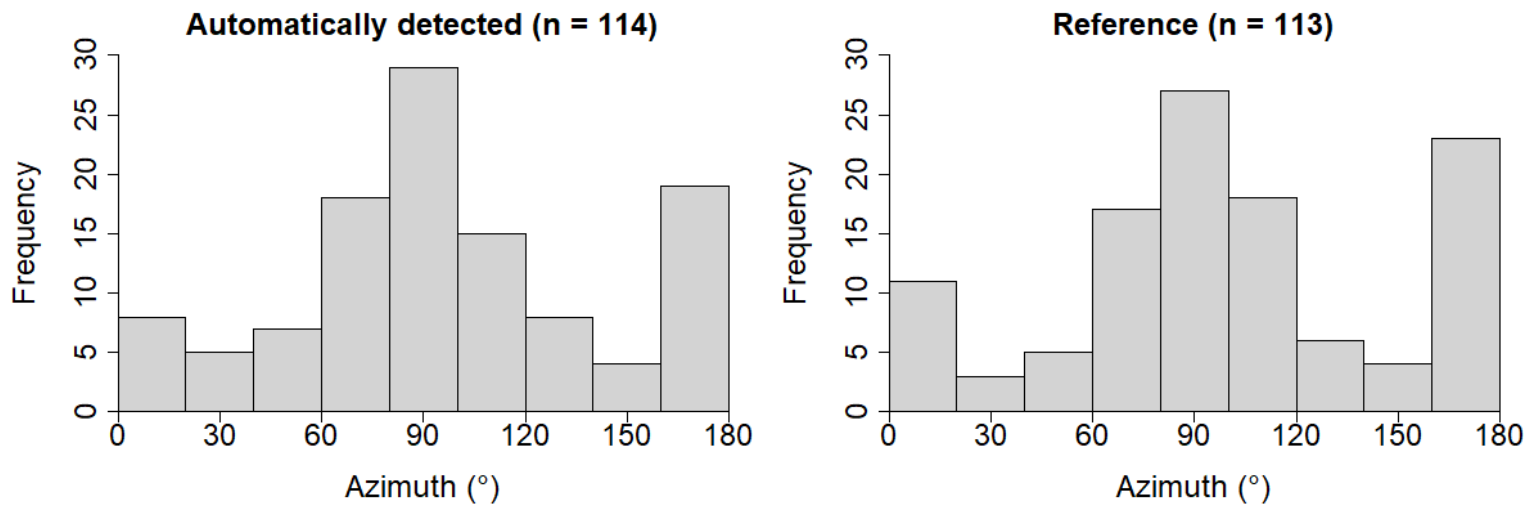

Figure 9. Distribution of the stem orientations (azimuth) in degrees on sample site Frohn_02; $0^{\circ}$ indicates a north-south orientation.
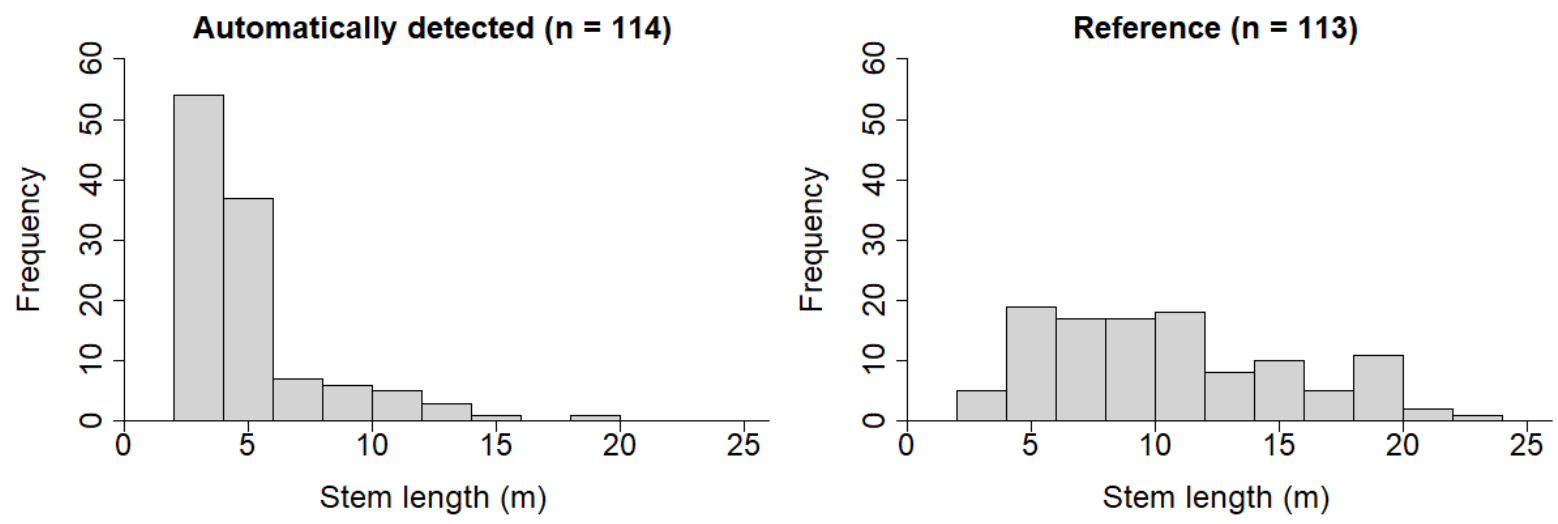

Figure 10. Distribution of the stem lengths on sample site Frohn_02.

\subsection{Summary Results for All 36 Sample Sites}

The number of automatically detected stems per sample blowdown area generally corresponded well with the reference data (Figure 11). Pearson's correlation coefficient between the estimated number of stems per sample blowdown area and the reference data was $r=0.65(p<0.001)$. The estimate was systematically higher than the reference (bias $=7.7 \%$ ). 


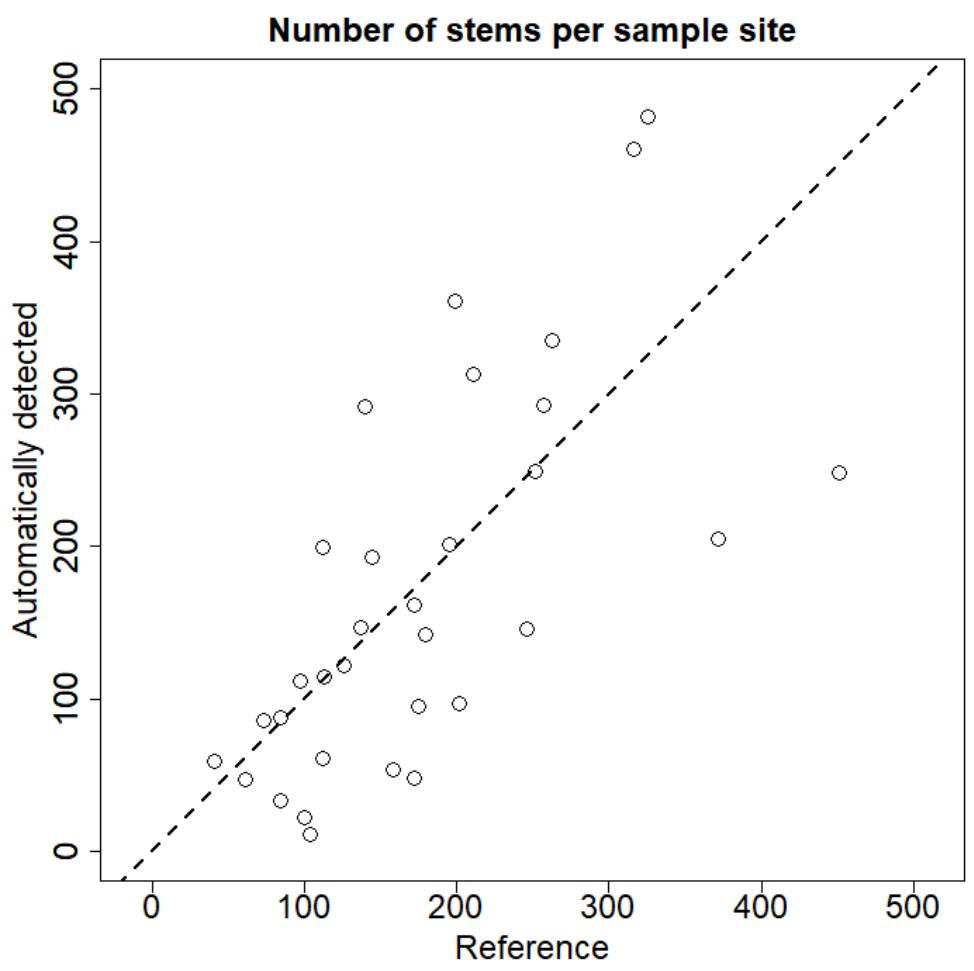

Figure 11. Correspondence of the number of automatically detected stems with the reference data on $n=38$ sample sites. The dashed line is the 1:1 line.

Statistically significant differences $(p<0.05)$ between the spatial distribution of stem centroids obtained using automatic detection and the reference data could only be found on $8.3 \%$ of all sample blowdown areas using Fasano-Franceschini tests with Holm correction for alpha inflation (Figure 12). Consequently, in $91.7 \%$ of all sample blowdown areas, the spatial distribution of stem centroids obtained using automatic detection was indistinguishable from the reference data.

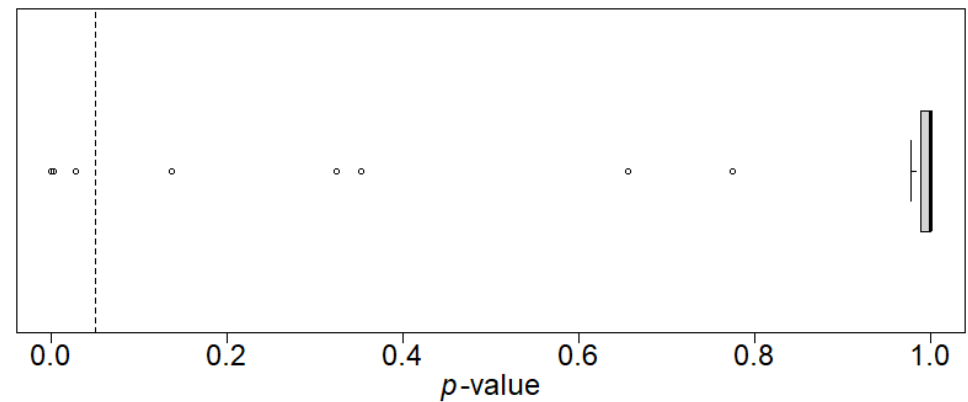

Figure 12. $p$-values of the Holm-corrected Fasano-Franceschini tests of the spatial distributions of estimated stem centroid positions against the reference data on $n=36$ sample blowdown areas. The dashed line indicates the $p=0.05$ threshold.

Statistically significant differences $(p<0.05)$ between the distributions of stem orientation angles obtained using automatic detection and the reference data could only be found in $8.3 \%$ of all sample blowdown areas using Kolmogorov-Smirnov tests with Holm correction (Figures 12 and 13). Consequently, in $91.7 \%$ of all sample blowdown areas, the spatial distribution of stem centroids obtained using automatic detection was indistinguishable from the reference data. 


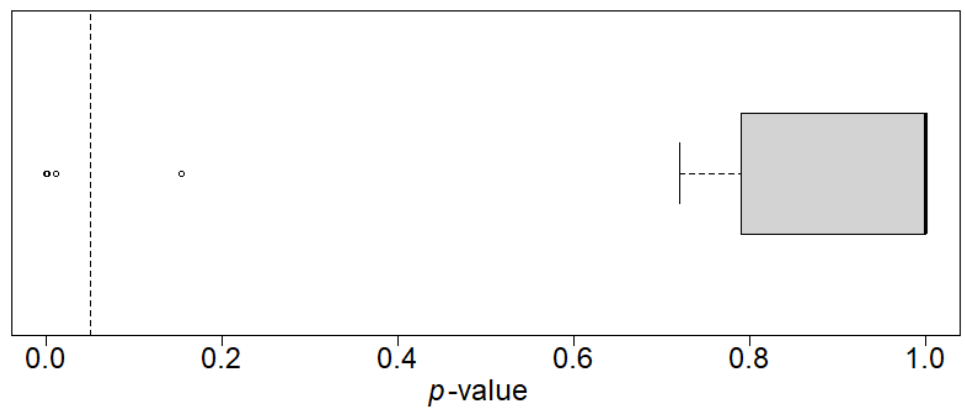

Figure 13. $p$-values of the Holm-corrected Kolmogorov-Smirnov tests of the distributions of estimated stem orientation angles against the reference data on $n=36$ sample blowdown areas. The dashed line indicates the $p=0.05$ threshold.

Statistically significant differences $(p<0.001)$ between the distributions of stem lengths obtained using automatic detection and the reference data were found on all sample blowdown areas using Kolmogorov-Smirnov tests with Holm correction for alpha inflation. The stem lengths obtained with the automatic procedure were systematically lower (bias $=-60 \%$ ) than the reference (Figure 14).
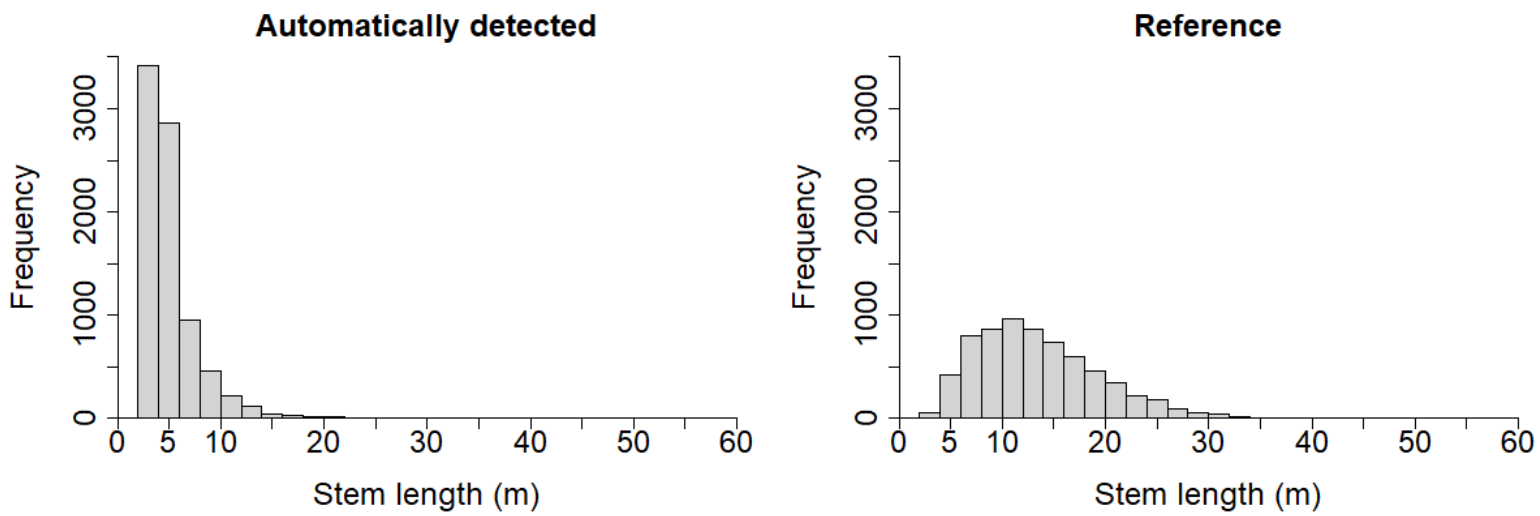

Figure 14. Distribution of the stem lengths.

\section{Discussion}

\subsection{Accuracy Assessment}

For sample blowdown areas with a high number of stems arranged in piles (e.g., Figure 2d), it was not possible to unambiguously assign automatically detected stems to reference stems and vice versa. Thus, calculations of the commission and omission errors was not possible in these cases. Instead, correspondence of the number, spatial distribution and orientation of the automatically detected stems with the reference data was reported. We acknowledge the problem that missing commission and omission error values may hamper the comparability of the results with other studies.

However, from a forest operations perspective, the information on commission and omission errors is not essential. For salvage harvest operation planning, it is necessary to have information on the terrain and on the spatial distribution and density of stems, as well as their orientation. This information allows for planning strip roads and cable yarding lines and selecting the appropriate harvesting system (from partially to fully mechanized). Thus, our approach for accuracy assessment is certainly somewhat unconventional; however, it is precisely tailored to information needs for forest operations planning.

\subsection{Advantages of the LSD Algorithm over Existing Approaches}

Classic edge detection techniques, such as Sobel, Prewitt, Laplacian and Canny [55-59], can be applied for the automatic detection of all possible forms of edges; however, this 
requires post-processing and filtering in order to isolate stems from other forms of edges. Hough transformation was found to be an efficient tool for this task [32]; however, it requires additional steps in the workflow and a noteworthy amount of processing power has to be spent on this.

In contrast, the LSD algorithm seems to be a straightforward solution to this problem, as only linear edges are detected by the algorithm. Thus, the necessary amount of postprocessing is drastically reduced, the workflow for stem detection is simplified and the necessary amount of processing power is reduced.

\subsection{Limitations of Data and the Proposed Methodology}

Depending on the research question, fallen stems are sometimes assessed down to a caliper threshold of just $2.5 \mathrm{~cm}$ in diameter [60]. The spatial resolution of the available aerial images with a GSD ranging between $11.84 \mathrm{~cm}$ and $20.02 \mathrm{~cm}$ inhibits the detection of features that small. We assume that a higher spatial resolution of the aerial photos would allow us to also detect smaller stems.

The spatial distributions of stem centroids and distribution of stem azimuths could be automatically derived for $91.7 \%$ of all sample sites. However, for a few sample sites, statistically significant differences between the estimate and the reference were observed. Aerial images of these sample sites were of clearly substandard quality, down to a degree that visual interpretation was hardly possible (Figures 1 and 15). We consciously decided not to exclude the images from our analyses; instead, we also tested the proposed methodology with these low-quality images to assess its limitations. For $100 \%$ of the images with qualities as presented in Figure $2 a-d$, the spatial distribution of automatically detected stem centroids and distribution of stem azimuths did not show a significant difference to the reference data.

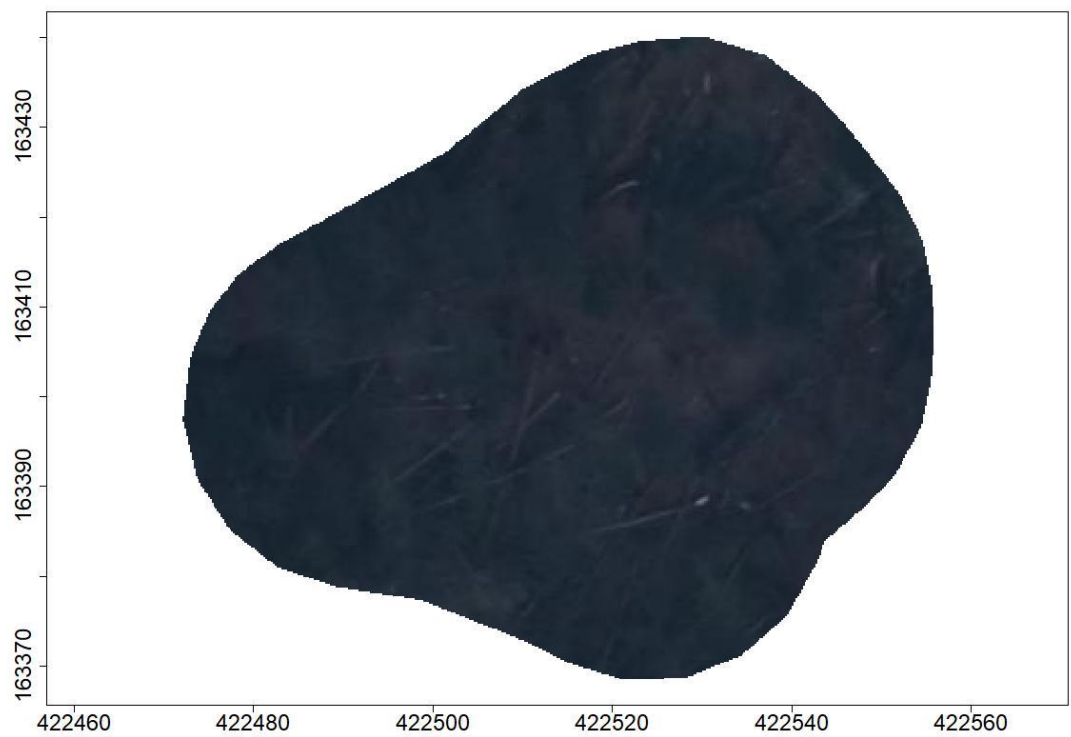

Figure 15. Exemplary sample site Ploecken_10, where the automated detection of fallen stems failed for images of this quality level. Coordinates are in meters and in the "MGI/Austria GK M31" coordinate reference system (EPSG-code: 31258).

In some of the aerial images, the number of stems was overestimated, as harsh shadows or rock edges were detected as linear features by the LSD algorithm, while in other images, the contrast was so low that many stems were not detected by the algorithm. Consequently, the linear relationship between the observed and predicted number of stems was only moderately tight $(r=0.65)$. Applying the methodology to aerial images of better quality would certainly yield higher values of Pearson's correlation coefficient. 
A principal limitation of the proposed methodology is its inability to assess downed trees' volume. The estimated stem lengths were systematically lower than the reference measures, showing a substantial bias of $-60 \%$, and even in the case where the problems in length estimation could be solved, trees were represented by lines and not by polygons such that no diameter estimation could be derived. In cases where the downed volume is the target variable, the proposed methodology may thus only be used as a first step, i.e., for stem detection, while other techniques (e.g., [14,30]) must be applied for volume estimation.

\subsection{Usability of the Proposed Methodology}

The proposed methodology is completely implemented in the statistical language and environment $R$ [39]. $R$ is free software, where it is distributed under the terms of the GNU General Public License, and thus, freely accessible. Hardware requirements are moderate; we seamlessly ran the workflow on a notebook with an Intel 8th generation i7 CPU and 16 GB of RAM within less than one hour computation time, i.e., less than 2 min computation time per sample blowdown area.

\section{Conclusions}

The proposed methodology was able to automatically and accurately detect the frequency, position, spatial distribution and orientation of fallen stems from aerial images. The gained information can be used for the optimized planning of salvage harvesting in the future and may thus help to reduce consequential bark beetle calamities after storm events.

Author Contributions: Conceptualization, T.R., A.N. and K.S.; methodology, T.R.; software, T.R.; validation, T.R., C.G. and R.K.; formal analysis, T.R. and R.K.; investigation, T.R.; data curation, T.R., C.G. and R.K.; writing—original draft preparation, T.R.; writing—review and editing, T.R., C.G., A.N. and K.S.; visualization, T.R.; funding acquisition, A.N. and K.S. All authors have read and agreed to the published version of the manuscript.

Funding: This research was funded by the Austrian Federal Ministry of Agriculture, Regions and Tourism; the cooperation platform Forestry, Timber and Paper; and the forest company Mayr-MelnhofSaurau under project Digi4+ (project number 101 470, https: / dafne.at/ projekte/digi4 (accessed on 2 December 2021)).

Data Availability Statement: Restrictions apply to the availability of data: aerial images were obtained from the Carinthian forest service and are available from the authors only with the explicit permission of the Carinthian forest service.

Acknowledgments: The authors appreciate the support that was given by the forest owners and the team of the Carinthian Forest Service, in particular, Christian Matitz, Clemens Wassermann and Guenter Kronawetter.

Conflicts of Interest: The authors declare no conflict of interest. The funders had no role in the design of the study; in the collection, analyses, or interpretation of data; in the writing of the manuscript; or in the decision to publish the results.

\section{References}

1. Schelhaas, M.-J.; Nabuurs, G.-J.; Schuck, A. Natural disturbances in the European forests in the 19th and 20th centuries. Glob. Chang. Biol. 2003, 9, 1620-1633. [CrossRef]

2. Thom, D.; Seidl, R.; Steyrer, G.; Krehan, H.; Formayer, H. Slow and fast drivers of the natural disturbance regime in Central European forest ecosystems. For. Ecol. Manag. 2013, 307, 293-302. [CrossRef]

3. Schlyter, P.; Stjernquist, I.; Bärring, L.; Jönsson, A.M.; Nilsson, C. Assessment of the impacts of climate change and weather extremes on boreal forests in northern Europe, focusing on Norway spruce. Clim. Res. 2006, 31, 75-84. [CrossRef]

4. Usbeck, T.; Wohlgemuth, T.; Dobbertin, M.; Pfister, C.; Bürgi, A.; Rebetez, M. Increasing storm damage to forests in Switzerland from 1858 to 2007. Agric. For. Meteorol. 2010, 150, 47-55. [CrossRef]

5. Blennow, K.; Andersson, M.; Bergh, J.; Sallnäs, O.; Olofsson, E. Potential climate change impacts on the probability of wind damage in a south Swedish forest. Clim. Chang. 2010, 99, 261-278. [CrossRef]

6. Blennow, K.; Olofsson, E. The probability of wind damage in forestry under a changed wind climate. Clim. Chang. 2007, 87, 347-360. [CrossRef] 
7. Seidl, R.; Thom, D.; Kautz, M.; Martin-Benito, D.; Peltoniemi, M.; Vacchiano, G.; Wild, J.; Ascoli, D.; Petr, M.; Honkaniemi, J.; et al. Forest disturbances under climate change. Nat. Clim. Chang. 2017, 7, 395-402. [CrossRef]

8. European Forest Institute. Spruce monocultures in Central Europe-problems and prospects. In Proceedings of the International Workshop, Brno, Czech Republic, 22-25 June 1998; Klimo, E., Hager, H., Kulhavý, J., Eds.; European Forest Institute: Joensuu, Finland, 2000; pp. 1-208.

9. Marini, L.; Økland, B.; Jönsson, A.M.; Bentz, B.J.; Carroll, A.; Forster, B.; Grégoire, J.-C.; Hurling, R.; Nageleisen, L.M.; Netherer, S.; et al. Climate drivers of bark beetle outbreak dynamics in Norway spruce forests. Ecography 2017, 40, 1426-1435. [CrossRef]

10. De Groot, M.; Ogris, N.; Kobler, A. The effects of a large-scale ice storm event on the drivers of bark beetle outbreaks and associated management practices. For. Ecol. Manag. 2018, 408, 195-201. [CrossRef]

11. Jirikowski, W.; Pröll, W. Krisenmanagement nach Windwurf (Crisis management after windthrow disasters). BFW-Prax 2003, 1, 3-5.

12. European Agency for Safety \& Health at Work. E-Fact 29-Occupational Safety and Health in Europe's Forestry Industry I Safety and Health at Work; European Agency for Safety \& Health at Work: Bilbao, Spain, 2008.

13. Sullman, M.J.; Kirk, P.M. Harvesting Wind Damaged Trees: A Study of the Safety Implications for Fallers and Choker Setters. Int. J. For. Eng. 2001, 12, 67-77. [CrossRef]

14. Kärhä, K.; Anttonen, T.; Poikela, A.; Palander, T.; Laurén, A.; Peltola, H.; Nuutinen, Y. Evaluation of Salvage Logging Productivity and Costs in Windthrown Norway Spruce-Dominated Forests. Forests 2018, 9, 280. [CrossRef]

15. Self, B. Tornado and Straight-Line Wind Damage to Hardwood Stands: Frequently Asked Management Questions; Publication 2683; Mississippi State University: Hood Rd, MS, USA, 2021.

16. Centre Technique du Bois et de l'Ambeulement. Technical Guide on Harvesting and Conservation of Storm Damaged Timber; Centre Technique du Bois et de l'Ambeulement: Paris, France, 2004.

17. Ståhl, G.; Ringvall, A.; Fridman, J. Assessment of Coarse Woody Debris: A Methodological Overview. Ecol. Bull. 2001, 49, 57-70.

18. Bütler, R.; Schlaepfer, R. Spruce snag quantification by coupling colour infrared aerial photos and a GIS. For. Ecol. Manag. 2004, 195, 325-339. [CrossRef]

19. Polewski, P.; Shelton, J.; Yao, W.; Heurich, M. Instance segmentation of fallen trees in aerial color infrared imagery using active multi-contour evolution with fully convolutional network-based intensity priors. ISPRS J. Photogramm. Remote Sens. 2021, 178, 297-313. [CrossRef]

20. Pasher, J.; King, D.J. Mapping dead wood distribution in a temperate hardwood forest using high resolution airborne imagery. For. Ecol. Manag. 2009, 258, 1536-1548. [CrossRef]

21. Einzmann, K.; Immitzer, M.; Böck, S.; Bauer, O.; Schmitt, A.; Atzberger, C. Windthrow Detection in European Forests with Very High-Resolution Optical Data. Forests 2017, 8, 21. [CrossRef]

22. Baumann, M.; Ozdogan, M.; Wolter, P.T.; Krylov, A.; Vladimirova, N.; Radeloff, V.C. Landsat remote sensing of forest windfall disturbance. Remote Sens. Environ. 2014, 143, 171-179. [CrossRef]

23. Wang, F.; Xu, Y.J. Comparison of remote sensing change detection techniques for assessing hurricane damage to forests. Environ. Monit. Assess. 2009, 162, 311-326. [CrossRef]

24. Vogelmann, J.; Tolk, B.; Zhu, Z. Monitoring forest changes in the southwestern United States using multitemporal Landsat data Remote Sens. Environ. 2009, 113, 1739-1748. [CrossRef]

25. Jonikavičius, D.; Mozgeris, G. Rapid assessment of wind storm-caused forest damage using satellite images and stand-wise forest inventory data. iForest Biogeosciences For. 2013, 6, 150-155. [CrossRef]

26. Rich, R.L.; Frelich, L.; Reich, P.; Bauer, M.E. Detecting wind disturbance severity and canopy heterogeneity in boreal forest by coupling high-spatial resolution satellite imagery and field data. Remote Sens. Environ. 2010, 114, 299-308. [CrossRef]

27. Marchi, N.; Pirotti, F.; Lingua, E. Airborne and Terrestrial Laser Scanning Data for the Assessment of Standing and Lying Deadwood: Current Situation and New Perspectives. Remote Sens. 2018, 10, 1356. [CrossRef]

28. Polewski, P.; Yao, W.; Heurich, M.; Krzystek, P.; Stilla, U. A voting-based statistical cylinder detection framework applied to fallen tree mapping in terrestrial laser scanning point clouds. ISPRS J. Photogramm. Remote Sens. 2017, 129, 118-130. [CrossRef]

29. Polewski, P.; Yao, W.; Heurich, M.; Krzystek, P.; Stilla, U. Detection of fallen trees in ALS point clouds using a Normalized Cut approach trained by simulation. ISPRS J. Photogramm. Remote Sens. 2015, 105, 252-271. [CrossRef]

30. Jensen, J.R. Remote Sensing of the Environment an Earth Resource Perspective Prentice Hall; Pearson: Saddle River, NJ, USA, 2000; pp. $1-592$.

31. Duan, F.; Wan, Y.; Deng, L. A Novel Approach for Coarse-to-Fine Windthrown Tree Extraction Based on Unmanned Aerial Vehicle Images. Remote Sens. 2017, 9, 306. [CrossRef]

32. Panagiotidis, D.; Abdollahnejad, A.; Surový, P.; Kuželka, K. Detection of fallen logs from high-resolution UAV images. N. Z. J. For Sci. 2019, 49, 49. [CrossRef]

33. Reder, S.; Mund, J.-P.; Albert, N.; Stadelmann, C.; Miranda, L.; Waßermann, L. Detektion von windgeworfenen Baumstämmen auf UAV-Orthomosaiken mit Hilfe von Neuronalen Netzen (Detection of wind-thrown tree trunks on UAV orthomosaics with the help of Neural networks). In Proceedings of the Forstwissenschaftliche Tagung (FoWiTa); Knoke, T., Holzer, D., Eds.; Technical University of Munich: Freising, Germany, 2021; p. 220.

34. Nothdurft, A.; Gollob, C.; Kraßnitzer, R.; Erber, G.; Ritter, T.; Stampfer, K.; Finley, A.O. Estimating timber volume loss due to storm damage in Carinthia, Austria, using ALS/TLS and spatial regression models. For. Ecol. Manag. 2021, 502, 119714. [CrossRef] 
35. Von Gioi, R.G.; Jakubowicz, J.; Morel, J.-M.; Randall, G. LSD: A Line Segment Detector. Image Process. Line 2012, 2, 35-55. [CrossRef]

36. Regen und Sturm: Ausmaß der Schäden Wird Sichtbar-News.ORF. Available online: https://orf.at/stories/3086341/ (accessed on 17 November 2021).

37. WLV Sturmtief Vaia 2018 Kärnten und Osttirol_Ein Jahr danach—Schäden und Maßnahmen; Bundesministerium für Nachhaltigkeit und Tourismus: Wien, Austria, 2018.

38. ESRI ArcGIS, Release 10; Environmental Systems Research Institute: Redlands, CA, USA, 2018.

39. Core Team. Core Team R: A Language and Environment for Statistical Computing. Version 2.3.4. 2009. Available online: http:/ / www.R-project.org/ (accessed on 6 October 2021).

40. Hijmans, R.J. Raster: Geographic Data Analysis and Modeling. R Package Version 2.8.19. 2019. Available online: https: / /CRAN.R-project.org/package=raster (accessed on 1 December 2021).

41. Barthelme, S. Imager: Image Processing Library Based on “CImg”, R Package Version 0.42.10. Available online: https://cran.rproject.org/package=imager (accessed on 1 December 2021).

42. Ochi, S. ImagerExtra: Extra Image Processing Library Based on "Imager", R Package Version 1.3.2. 2019. Available online: https: / / cran.r-project.org/package=imagerExtra (accessed on 1 December 2021).

43. Ooms, J. Magick: Advanced Graphics and Image-Processing in R, R Package Version 2.7.3. Available online: https://cran.rproject.org $/$ package $=$ magick (accessed on 1 December 2021).

44. Bivand, R.; Leisch, F.; Maechler, M. Pixmap: Bitmap Images/Pixel Maps, R Package Version 0.4.12. Available online: https: / / cran.r-project.org/package=pixmap (accessed on 1 December 2021).

45. Wijffels, J.; Grompone von Gioi, R. Detect Line Segments in Images, R Package Version 0.1.0. Available online: https:/ / cran.rproject.org/web/packages/image.LineSegmentDetector (accessed on 1 December 2021).

46. Von Gioi, R.G.; Jakubowicz, J.; Morel, J.-M.; Randall, G. LSD: A Fast Line Segment Detector with a False Detection Control. IEEE Trans. Pattern Anal. Mach. Intell. 2010, 32, 722-732. [CrossRef]

47. Desolneux, A.; Moisan, L.; Morel, J.-M. Meaningful Alignments. Int. J. Comput. Vis. 2000, 40, 7-23. [CrossRef]

48. Desolneux, A.; Moisan, L.; Morel, J.-M. From Gestalt Theory to Image Analysis: A Probabilistic Approach (Interdisciplinary Applied Mathematics); Springer: Berlin/Heidelberg, Germany, 2007; ISBN 03877-26357.

49. Jenks, G. The Data Model Concept in Statistical Mapping. Int. Yearb. Cartogr. 1967, 7, 186-190.

50. Rabosky, D.L.; Grundler, M.; Anderson, C.; Title, P.; Shi, J.; Brown, J.; Huang, H.; Larson, J.G. BAMMtools: An R package for the analysis of evolutionary dynamics on phylogenetic trees. Methods Ecol. Evol. 2014, 5, 701-707. [CrossRef]

51. Venables, W.N.; Ripley, B.D. Modern Applied Statistics with S, 4th ed.; Springer: New York, NY, USA, 2002; ISBN 0-387-95457-0.

52. Ness-Cohn, E. Fasano.Franceschini.Test: Fasano-Franceschini Test: A 2-D Kolmogorov-Smirnov Two-Sample Test, R Package Version 1.1.0. Available online: https:/ / cran.r-project.org/package=fasano.franceschini.test (accessed on 1 December 2021).

53. Aickin, M.; Gensler, H. Adjusting for multiple testing when reporting research results: The Bonferroni vs Holm methods. Am. J. Public Health 1996, 86, 726-728. [CrossRef] [PubMed]

54. Holm, S. A Simple Sequentially Rejective Multiple Test Procedure. Scand. J. Stat. 1979, 6, 65-70.

55. Ben, A.I.; Nicholas, O. Optimum Fuzzy based Image Edge Detection Algorithm. Int. J. Image Graph. Signal Process. 2017, 9, 44-55. [CrossRef]

56. Bausys, R.; Kazakeviciute-Januskeviciene, G.; Cavallaro, F.; Usovaite, A. Algorithm Selection for Edge Detection in Satellite Images by Neutrosophic WASPAS Method. Sustainability 2020, 12, 548. [CrossRef]

57. Dong, E.; Li, K.; Tong, J. FPGA Based Design and Implementation of Improved Edge Detection Algorithm using LOG Operator In Proceedings of the 2018 IEEE International Conference on Mechatronics and Automation (ICMA), Changchun, China, 5-8 August 2018; pp. 2092-2096.

58. Zhang, W.; Chen, Y.; Wang, H.; Chen, M.; Wang, X.; Yan, G. Efficient registration of terrestrial LiDAR scans using a coarse-to-fine strategy for forestry applications. Agric. For. Meteorol. 2016, 225, 8-23. [CrossRef]

59. Gunawan, T.S.; Yaacob, I.Z.; Kartiwi, M.; Ismail, N.; Za'Bah, N.F.; Mansor, H. Artificial Neural Network Based Fast Edge Detection Algorithm for MRI Medical Images. Indones. J. Electr. Eng. Comput. Sci. 2017, 7, 123-130. [CrossRef]

60. Harmon, M.E.; Franklin, J.F.; Swanson, F.J.; Sollins, P.; Gregory, S.V.; Lattin, J.D.; Anderson, N.H.; Cline, S.P.; Aumen, N.G.; Sedell, J.R.; et al. Ecology of coarse woody debris in temperate ecosystems. In Advances in Ecological Research; MacFadyn, A., Ford., E.D., Eds.; Academic Press: Orlando, FL, USA, 1986; Volume 15, pp. 133-302. 